\title{
Los sistemas constructivos de Francisco Gallardo
}

\begin{abstract}
Veo las líneas trazadas por los arquitectos y, a veces, son tan finas como un hilo de araña. Pero los axiomas de las matemáticas son diferentes. No son imágenes de cosas que me entran por los ojos de mi cuerpo. Las conoce quien las reconoce interiormente sin referencia a pensamiento alguno material. D e la misma manera puedo percibir los números de que nos servimos para contar las cosas. Pero el principio del número por el que contamos no es lo mismo. No es una imagen de las cosas que contamos, sino algo mucho más sólido.
\end{abstract}

San Agustín, ConfesionesX, I3

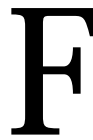

rancisco Gal I ardo eligió volcarse totalmente hacia su vocación artística a una edad relativamente tardía, tras una intensa actividad como diseñador gráfico. N o obstante que su obra no oculta formas y medios de expresión afines a los de otros creadores que comienzan a tener reconocimiento crítico desde finales de la década de los sesenta y durante toda la década de los setenta, el trabajo que ha desarrollado Gallardo puede interpretarse como el producto de un proceso particularmente personal, al margen de parámetros como generación o asimilación de tendencias compartidas con otros colegas. Teniendo como antecedente común el diseño gráfico y recurriendo ambos al manejo formal de la geometría euclidiana, podría establecerse un símil entre Vicente Rojo y Francisco Gallardo, pero esta simili- 


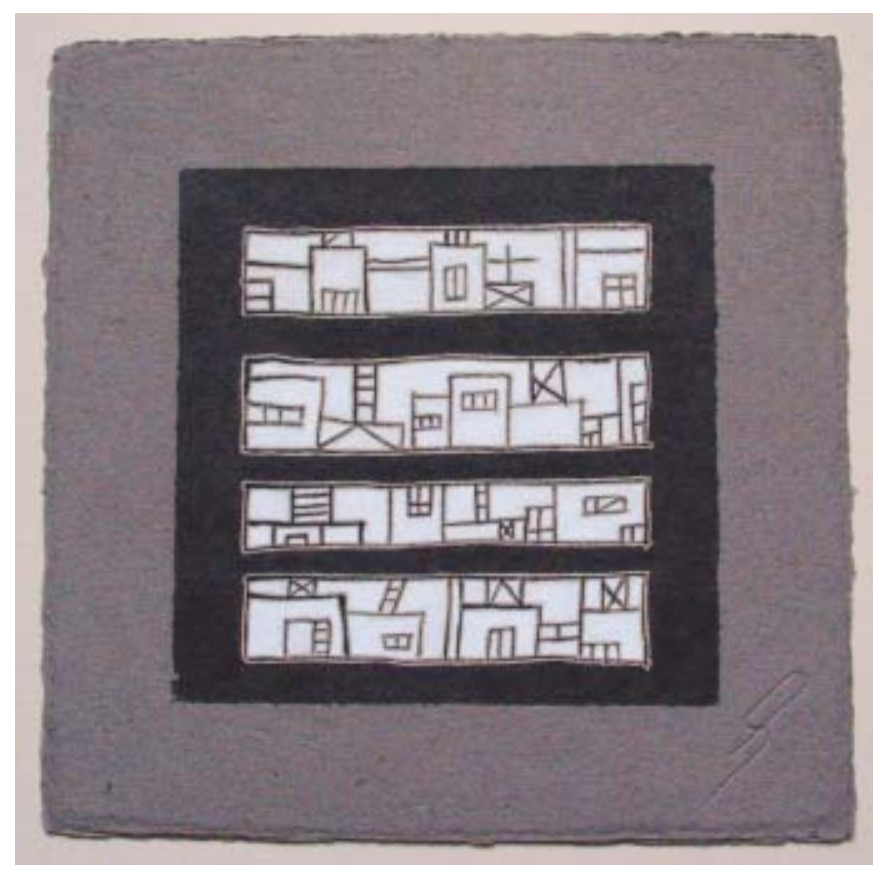

I. Francisco Gallardo, Dela sørieproyectos 10 , año: 2003, técnica mixta, medidas: $30 \times 30 \mathrm{~cm}$. Foto: Luis Gallardo.

tud sería a partir de una mirada superficial, usando este calificativo simplemente como metáfora topológica, pues la actitud con que los dos autores asumen y desarrollan los materiales y la geometría es significativamente distinta. No siendo un ermitaño absoluto, G allardo atiende con interés lo que acontece en los escenarios del arte contemporáneo de M éxico, pero, no obstante que su producción ha sido presentada con cierta frecuencia en foros museográficos, lo cierto es que su vasta obra se ha desarrollado desatenta a los circuitos públicos del arte y desatendida por los espacios de análisis y crítica artística; ajeno a la autopromoción de su trabajo, éste se concentra en una relación, intensamente física, con los materiales que transmuta y con los problemas técnicos y teóricos que desea resolver con ellos. No existe en los procesos creativos que realiza una disociación entre la reflexión y la manipulación material: ambas se imbrican en un desarrollo que, a partir de series, 


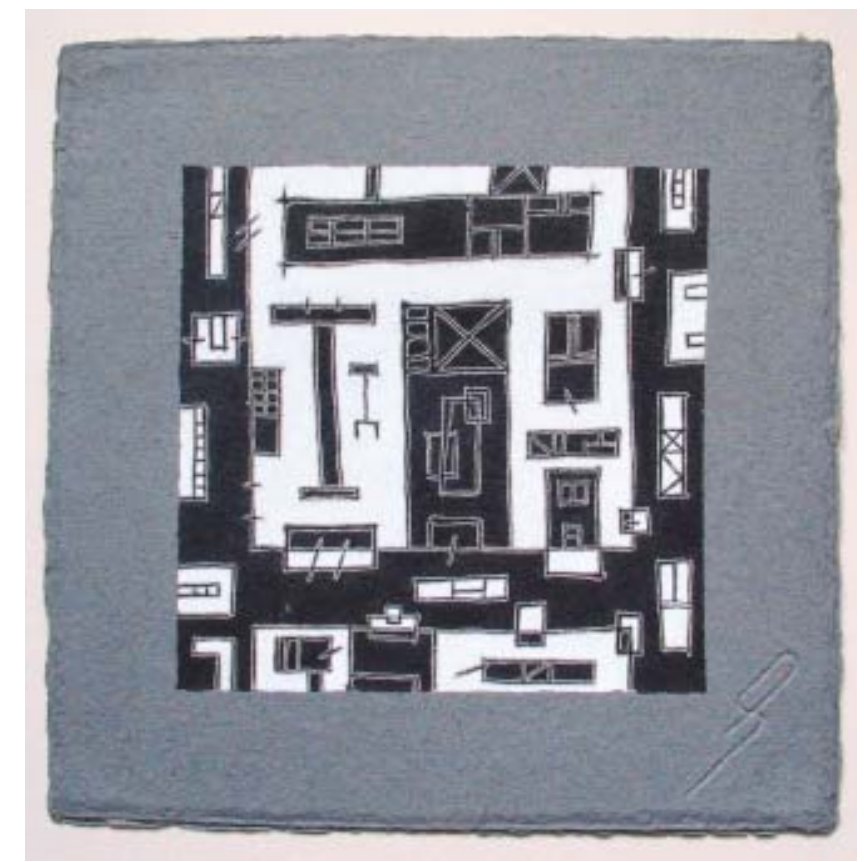

2. Francisco $G$ allardo, Dela serieproyetos $I I$, año: 2003, técnica mixta, medidas: $30 \times 30 \mathrm{~cm}$. Foto: Luis Gallardo.

parece agotar todas las posibilidades o variaciones que una iniciativa creativa puede generar. Ciertas inquietudes creativas son estimuladas por las posibilidades técnicas y formales de un material o un proceso, o bien éstos pueden ser el motivo que antecede a una inquietud creativa; esta simbiosis provoca alguna de las mencionadas series que, una vez terminadas o interrumpidas, puede ser seguida por otra aparentemente distinta en formas y técnicas. Lo que enlaza a las series, y lo que le imprime al conjunto del trabajo de Gallardo un sentido coherente y particular, es la capacidad del autor de encontrar un punto de sobrio equilibrio entre las posibilidades y las limitaciones de cada material o técnica utilizada, siendo este equilibrio una exhibición, al mismo tiempo virtuosa y discreta, de las maneras expresivas con que un material puede ser articulado, 0 de los medios con que una sustancia 0 un sistema geométrico puede expresar su "naturaleza": su coherencia como orde- 
196

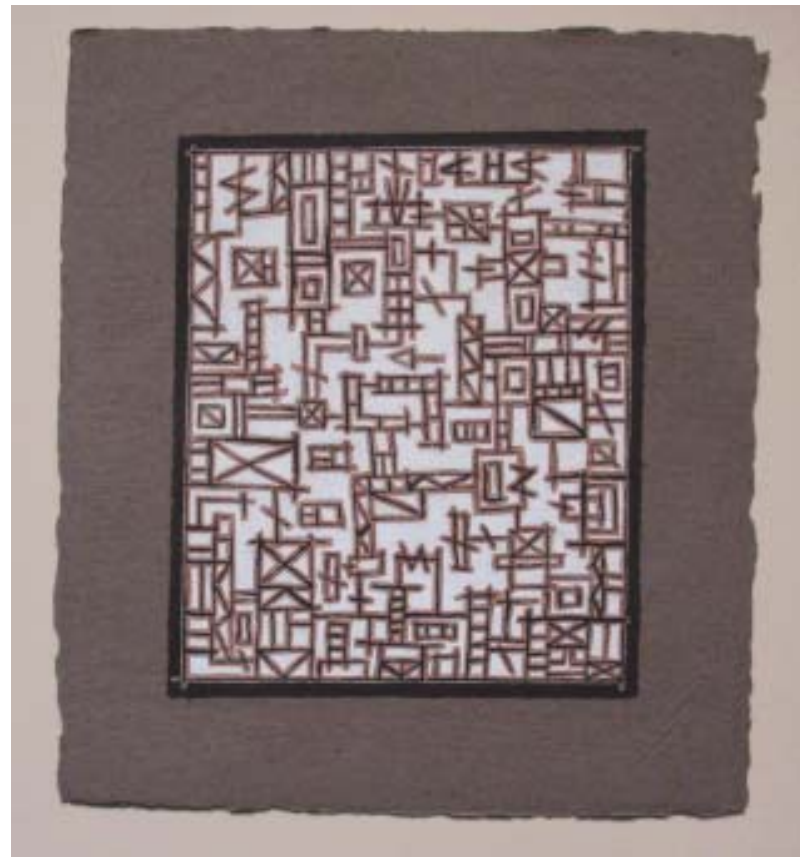

3. Francisco Gallardo, Dela scrieproyectos ${ }_{33}$, año: 2004, técnica mixta, medidas: 4I $\times 36 \mathrm{~cm}$. Foto: Luis Gallardo.

nación subjetiva. Por ejemplo, Gallardo hace obra depapel, no sobrepapel; los trazos y los contornos no son elementos agregados al soporte, ya que están vinculados a sus fibras, convirtiendo a la obra en un objeto que la fotografía sólo reproduce parcialmente. Lo mismo ocurre con el cemento o con la lámina metálica; como si fuera un tallador de madera que guiara su gubia a partir de los nudos y contornos que delinean las vetas, las obras de $G$ allardo se perciben como una solución plástica congruente con lo que es fluido y accidental en los materiales donde ejerce su oficio.

Al que escribe estas líneas le tiene sin cuidado - y supongo que también le despreocupa a Gallardo- que la soltura, virtuosismo y oficio capaz con que el artista manipula sus creaciones tenga una simpatía, en concepto o en actitud, con el trabajo de los grandes artesanos "tradicionales". La imperante suspicacia en torno a la habilidad o la manualidad en el contexto del arte 


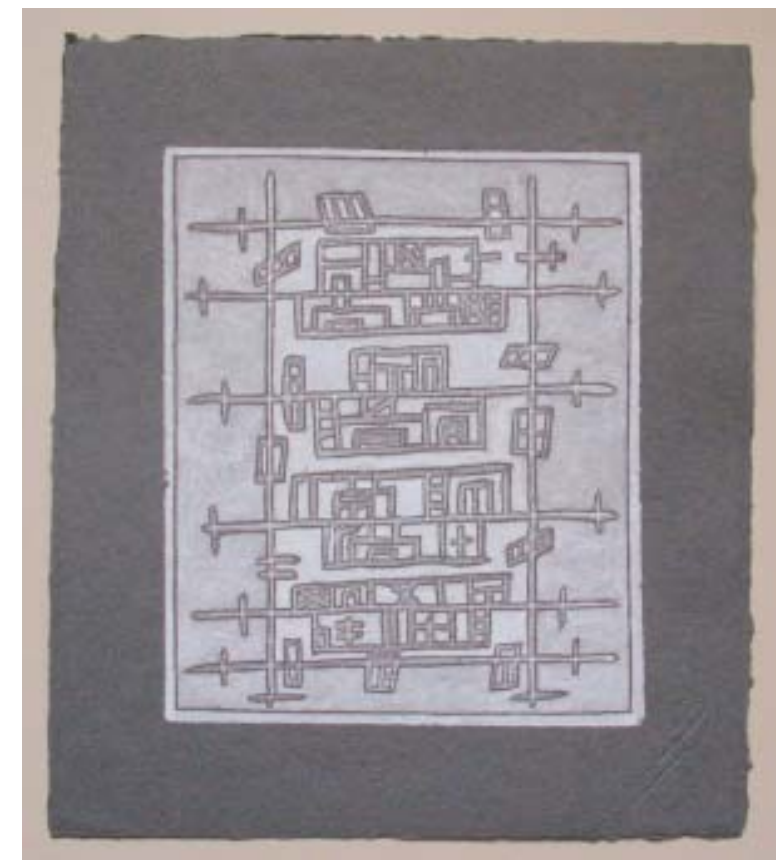

4. Francisco Gallardo, Dela serieproyectos $I_{4}$, año: 2004, técnica mixta, medidas: $4 \mathrm{I} \times 36 \mathrm{~cm}$. Foto: Luis Gallardo.

contemporáneo es un prejuicio, ya casi centenario, que no tolera un sencillo ejercicio de análisis, al tiempo que la segmentación de la creación contemporánea entre artistas y artesanos, y entre tradición e innovación, entre original y copia, denota un clasismo intelectual, un "formalismo" conceptual, que estorba para vincular, de manera distinta a la de la especialización académica, al arte contemporáneo y a su exégesis con otras áreas del pensamiento y de la práctica creativa. Una de esas maneras distintas de aproximación y vinculación, en el caso de la obra de Gallardo, la encuentro entre una parte importante de su producción y los sistemas de representación gráfica arquitectónica, no refiriéndome específicamente al dibujo técnico utilitario cuyas convenciones generales se establecen a partir del siglo xvi, sino también a los trazos arquitectónicos y urbanos con que artistas, maestros de obras y legos han representado los edificios, los trazos urbanos y las cartografías desde ha- 
198

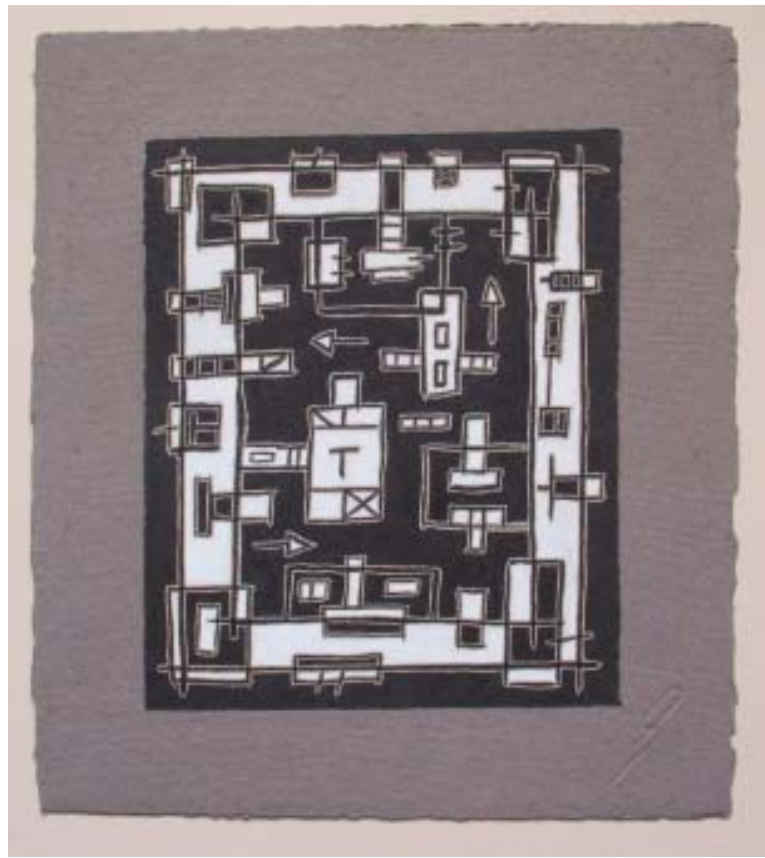

5. Francisco Gallardo, Dela srieproyectos Is, año: 2004, técnica mixta, medidas: 4I X 36 cm. Foto: Luis Gallardo.

ce, por lo menos, 2500 años. En muchas de las mencionadas obras de papel de Gallardo, la mirada identifica, de manera casi inmediata, contornos arquitectónicos, vías, bordes, barrios y señales urbanas, sin que esta identificación implique que el artista haya recurrido necesariamente a convenciones simbólicas o de representación específicas; aun evadiendo referencias urbanas tan concretas, el que mira reconoce en el diseño del papel - más que un simple trazo geométrico- una construcción: una serie de elementos que, por medio de un proceso determinado, se articulan en un sistema. Esta construcción, por supuesto, depende de la memoria, de las referencias y las preferencias del que percibe, y el versado en términos de representación arquitectónica reconocerá en la obra de Gallardo lo que le conviene; pero el reconocimiento en ésta de sistemas topográficos, o de esquemas constructivos, es una actitud compartida por muchos que la han mirado. Este conjunto creativo es eviden- 
temente un producto de su tiempo, más allá de que al gunos pretendan calificarlo de "anticuado" o "anacrónico" con respecto a las tendencias estéticas vigentes. Y, reflexionando, imputarle los valores de lo anacrónico - interpretando este calificativo como aquello que está fuera de lo que concierne al tiempo- no perjudica en absoluto el interés que genera: posiblemente una gran cualidad de la producción de $G$ allardo reside en su capacidad de referirnos o evocarnos órdenes de composición que han sido ejercidos o imaginados en distintos lugares y en distintas épocas, órdenes que derivan de la abstracción tanto de procesos identificados en la naturaleza como de los medios con los que los humanos construimos e interpretamos nuestros espacios; órdenes que consisten en identificar, en las cosas que existen y en las que se imaginan, un principio elemental - de naturaleza numérica, matemática y geométrica - que se desarrolla hasta niveles complejos, pudiéndose reconocer, a pesar de la complejidad formal que se al cance, la matriz original.

$\mathrm{N}$ o vivimos en cartografías ni transitamos en mapas ni vivimos en planos arquitectónicos; nuestra experiencia del espacio y del tiempo es subjetiva y frecuentemente ajena a los model os de interpretación matemática que suponemos objetivos y universales. Pero la manera en que nuestra conciencia está configurada y las maneras en que nos comunicamos, encuentran en los sistemas numéricos y geométricos medios de interpretación, de expresión y de representación. Para algunos, estos medios evocan principios de naturaleza esotérica, principios ocultos para el entendimiento y la vivencia mundanos. Pero la más sencilla expresión geométrica, como lo meditó san Agustín, es ya una aparición en el mundo de lo sensible, una figura que permite un camino hacia la interpretación. Sin la necesidad de dedicarse hoy, como antaño, a la confección de logotipos, Gallardo sigue siendo un comunicador gráfico, un "exotérico", un confeccionador de patrones que permiten interpretaciones abiertas, como todas las que derivan de símbolos, pero que, en su apertura, sugieren sistemas inteligibles, comunicables aunque no verbales, para la interpretación de la realidad. Este hecho (esta sugerencia) también podría vincular la producción de Gallardo con la de otros artistas y artesanos, muchos de ellos anónimos, que realizaron su obra en concordancia con tradiciones distintas a las corrientes hegemónicas que orientarán al arte de 0 ccidente a partir de la modernidad. \$ 